\title{
Memória e Ética na Representação do Holocausto
}

Ana Carolina Gonçalves Garritano*

Sem palavra, não há memória, sem memória, não há cultura e sem cultura não há valores. O ser ético é necessariamente um ser humano identificado com determinada rede de valores (cultura) - logo, dotado de memória e capaz de domínio e reprodução da linguagem simbólica (a palavra). Pensar sobre a ética na representação cinematográfica significa pensar a posição da qual o cineasta emite um discurso. O cineasta ético é aquele capaz de refletir sobre sua cultura e sobre si, antes de emitir um ponto de vista sobre o outro.

A memória é um elemento constitutivo da identidade humana. Pode-se afirmar isso ao pensar que a identidade se constrói no campo simbólico da linguagem e que a palavra é aquilo que nos distingue dos outros animais: nascemos, aprendemos a falar e introjetamos (memorizamos), pela palavra, conhecimentos, informações, valores e nomenclaturas que existem somente nesta esfera simbólica. Através do domínio sobre ela, construímos nossa subjetividade - condição do sujeito humano. E, construindo nossas subjetividades, criamos culturas distintas - grupos de indivíduos que partilham saberes, valores e comportamentos comuns.

O domínio da palavra permite que nos afastemos da coisa em si. Podemos nos referir ao objeto que usamos para sentar porque ele tem um nome ("cadeira") que o simboliza. Não é necessário que haja uma cadeira onde estou para que eu fale dela. A linguagem permite, assim, que o ser humano não se limite ao aqui e agora - à concretude das coisas - e que possa, graças à sua dimensão simbólica, pensar no passado e planejar ou imaginar o futuro. Permite, portanto, a construção da memória.

Deste raciocínio pode-se inferir que a culpa é exclusividade daqueles devidamente inseridos na linguagem, que possuem a capacidade de se afastar do aqui e do agora e, assim, rever o passado e se arrepender de algo ou projetar no futuro uma possível punição e deixar de cometer algum tipo de infração. O ser ético é, portanto, aquele capaz de rever atos - em um processo de julgamento tardio - ou de antecipar questões (ou punições) - em um processo de reflexão sobre os comportamentos, leis e tradições que regem sua cultura. Logo, o ser ético é aquele capaz de reflexão.

Quais são as responsabilidades, então, do profissional de cinema? Enquanto sujeito humano, cultural e dotado de memória, o profissional de cinema já está inserido no campo da ética, pois todo ser humano que se comunica e se entende como pessoa já é ético, mesmo que seus comportamentos não o sejam. Enquanto sujeito que quer produzir narrativas visuais sobre o mundo, ou sobre a realidade específica em que vive, o cineasta tem uma grande responsabilidade para com a memória de sua cultura e os membros da mesma. Sempre.

\footnotetext{
* Aluna do curso de Comunicação Social, período 2014.1
} 
Mesmo que ele as ignore totalmente, ele estará agindo com referência a ela, de alguma forma. Ou seja, não há como ignorar a ética nesta profissão.

Algumas pessoas acreditam que a estética e a ética sejam opostas, ou que a arte seja apolítica em sua essência, mas existe outro ponto de vista possível. Primeiramente, ser político não significa necessariamente ter um partido e lutar por mudanças de leis. Ser político é ter consciência da realidade em que se vive, ter conhecimento de sua cultura, de sua individualidade e ter memória e ser livre para ter um ponto de vista sobre esta realidade, sendo responsável por suas ações e pensamentos. Ser político, portanto, é ser livre para pensar e adotar uma posição dentro do caldo da valores, comportamentos, acontecimentos e tradições, que é a cultura. E ser artista...? Não é expressar um ponto de vista sobre o mundo...? Portanto, todo artista é político.

O cineasta capta a realidade existente, a reorganiza e a expõe de volta em uma tela. Ele emite, a todo tempo, um ponto de vista sobre sua cultura - uma forma de discurso que sempre envolve a ética e a estética. Ele pode, ainda, produzir uma narrativa sobre uma outra cultura - o que torna a discussão ainda mais complexa. Não é possível fazer um filme que não seja político - ou ele está sendo ético, ou não ético, ou ignorando a ética. Toda adoção de perspectiva envolve um posicionamento no mundo - e este posicionamento pode ser entendido como ética.

Vamos analisar a abordagem de dois cineastas diferentes, em filmes de períodos completamente distintos e de gêneros distintos, sobre um mesmo acontecimento - polêmico e traumático, quando se trata de ética: o Holocausto. "Noite e Neblina", documentário de 1955 de Alain Resnais, considerado o primeiro filme sobre os campos de concentração e "O Leitor", drama ficcional de 2008. Ambos revelam importantes aspectos da relação dos indivíduos modernos com a memória do Holocausto, sob abordagens bem diferentes. Pensemos um pouco sobre a postura ética do cineasta diante da tarefa de fazer um filme sobre esse assunto... como representar o irrepresentável?

Consideremos o texto "Modernidade e Holocausto" no qual Zygmund Bauman condena as teorias (sobre o Holocausto) que fragmentam a realidade e marginalizam o acontecimento com o objetivo de explicá-lo como se fosse produto de uma nação, de um tempo e de circunstâncias restritas. Segundo ele, esse tipo de teoria não permite a verdadeira compreensão da sociedade que produziu essa catástrofe:

\footnotetext{
Enquanto definido, por assim dizer, como a continuação do antisemitismo por outros meios, o Holocausto parece ser um conjunto unitário, um episódio único, que talvez lance alguma luz sobre a patologia da sociedade em que ocorreu mas que dificilmente acrescenta algo à nossa compreensão do estado normal dessa sociedade.
}

Zygmunt Bauman. 'Modernidade e Holocausto".

Para Bauman, o Holocausto deve dizer respeito a todos nós, sujeitos ocidentais modernos, e não só ao povo alemão. A tentativa de justificar essa catástrofe como obra de um 
período que passou e uma gente específica, segundo ele, significa um abrandamento da culpa que mancha a identidade de toda a sociedade moderna, "civilizada" e "avançada".

Esse texto nos permite pensar sobre a postura ética dos autores destas teorias. Se ser ético é ser livre para se posicionar de acordo com a sua cultura e valores, toda atitude ética exige a compreensão da cultura à qual pertencemos. Ou, ao menos, que nos perguntemos: qual é a minha cultura? O que me formou como sujeito? Neste caso específico, a atitude verdadeiramente ética seria que estes autores se perguntassem profundamente, antes de escreverem suas teorias: seriam os sujeitos alemães que viveram o Holocausto tão diferentes de mim? Por que?

A teoria sociológica de Bauman, em relação a tantas outras, analisa mais fielmente o significado da produção e revitalização da memória do Holocausto. No entanto, por ser um estudo do campo das ciências sociais, que é uma racionalização dos comportamentos humanos, se encontra ainda restrita a esse campo do saber que deve, de maneira lógica e coerente, estabelecer conclusões - como faz Bauman, ao afirmar que o Holocausto é um produto do homem moderno (e não tão e somente do povo alemão do período entre guerras).

Os filmes "Noite e Neblina" e "O Leitor", se analisados esteticamente, contribuem de uma outra forma para a análise da relação humana com a memória do Holocausto e sua representação ética. Apesar de muito distintos, o primeiro sendo um documentário de 1955 e o segundo um drama ficcional de 2008, eles produzem, juntos, um significado que vai um pouco além da Modernidade de Bauman. Analisá-los nos permite pensar sobre que perguntas se fizeram os cineastas antes de escreverem cada um desses filmes. Como eles tentaram conceber a sua identificação com os elementos envolvidos neste evento tão traumático - como eles avaliaram sua responsabilidade sobre a forma como falariam sobre o assunto... e o que falariam. Como eles tiveram a postura ética de se perguntar, durante a criação desses filmes: sobre o que eu estou falando, sobre quem e por que eu devo me posicionar sobre isso?

O documentário de Alain Resnais foi feito a pedido do Comitê de História da Segunda Guerra Mundial, por ocasião da comemoração do aniversário de extinção dos campos de concentração. O objetivo primário e explícito era, portanto, o de elaborar um documento que registrasse o início, meio e fim desses campos. A abordagem de Resnais poderia ter sido objetiva e confortante, no sentido de contar uma história que abarcou atrocidades, mortes e torturas...e que passou, mas não.

Resnais poderia ter adotado a recorrente "estética Discovery Channel" - aquela cientificamente objetiva, narrada distanciadamente por um locutor neutro, com mapas e imagens de arquivo. Contudo, o diretor faz uma abordagem que, além de registrar objetivamente o sofrimento dos milhões de inocentes dos campos, com imagens de arquivo fortes, traz uma narração subjetiva - e poética - de um ex-prisioneiro e imagens dos campos desativados e vazios. A inserção do relato pessoal confere inegável humanidade - e 
universalidade - ao acontecimento. E as imagens dos campos, desérticos e inofensivos, no presente, sugerem a latência de uma ameaça adormecida na memória:

\begin{abstract}
"No momento em que lhes falo... a água fria do pântano volta a encher as valas... uma água fria e opaca como nossa memória fraca. A guerra abrandou... um olho sempre atento. A grama fiel rebrotou na praça das chamadas. Uma vila abandonada, ainda cheia de ameaças. O crematório está fora de uso, como algo fora de moda. Nove milhões de mortos assombram essa paisagem. Quem de nós vigia esse estranho observatório para avisar da vinda de novos carrascos? Será que eles são diferentes de nós? Em alguma parte, entre nós há kapos com sorte, chefes ressurgidos, informantes... Há os que não acreditavam, ou só de vez em quando. E há nós, que olhamos estas ruínas... como se o velho monstro estivesse morto sob elas, que retomamos a esperança diante da imagem que se afasta como se sarássemos da peste centralizadora. Nós, que fingimos que isso pertenceu a um tempo, a um país. $E$ que não olhamos em volta de nós... E que não ouvimos o grito que não cala".
\end{abstract}

(Texto da sequência final de cenas de "Noite e Neblina")

Diferentemente das teorias criticadas por Bauman, esse registro do Holocausto não responsabiliza ninguém, nem circunscreve o evento a um período e região: narra como uma ferida na identidade da humanidade - uma ferida na natureza dos únicos seres capazes de produzir cultura, memória e ética. Aponta para o lado negro, amoral, que reside na natureza humana.

Alain Resnais, enquanto cineasta, enquanto produtor de um discurso que se permite artístico, por isso mais livre e menos racional, não oferece uma conclusão: não afirma que o Holocausto é produto da Modernidade. Isso, sem dúvida, poderia ser deduzido da frase final do texto. No entanto, poder-se-ia deduzir também que "o grito que não cala" está dentro de todos os seres humanos - desde o momento em que começamos a existir enquanto espécie: quando começamos a existir enquanto sujeitos necessariamente éticos - mas que nem todos, nem sempre, o são.

"O Leitor", filme ganhador de 5 Oscars, produzido em 2008, faz uma abordagem do Holocausto distinta e complementar a de Bauman e a de Alain Resnais. Como ambos, destaca o Holocausto como algo a se compreender - algo que diz respeito a todos nós. No entanto, de maneira esteticamente muito distinta: não desenvolve uma ciência social racionalizada e concluída e não tem a preocupação de fazer um documento histórico e documental sobre a memória do Holocausto.

O filme é um drama fictício que tem como tema central uma história de amor. Uma história entre dois sujeitos extremamente distintos quanto à classe social, idade e hábitos... mas que se apaixonam. O leitor é Michael, menino de 17 anos, aficionado por leitura e poesia, que se apaixona por Hanna, não leitora, quer dizer, uma mulher analfabeta, que lhe ensina sobre os prazeres imediatos da vida, como o sexo. O diretor propõe, portanto, a identificação entre um sujeito perfeitamente inserido na linguagem e outro que não compreende a simbologia das palavras. 
Ao longo do filme, percebe-se como Hanna não tem muita noção de sua própria subjetividade... a identidade, para ela, não é algo claro, ou relevante. Em um momento do filme, relativamente no início, quando eles já tinham se conhecido e dormido juntos algumas vezes, ele resolve perguntar seu nome. Ela, indignada, ou intrigada, pergunta por que ele quer saber. Ele responde, com obviedade, que era porque eles tinham estado juntos diversas vezes e ele nem sabia seu nome (algo básico para ele). Em outra cena, em que eles brigam, Michel pergunta por que é sempre ele quem pede desculpas... ela, irritada, responde que ele não tem que pedir desculpas, que ninguém tem que pedir desculpas.

O diretor nos mostra como Hanna não possui grande capacidade de reflexão sobre seus atos - porque a reflexão exige o distanciamento da coisa em si que, por sua vez, só ocorre através do domínio da palavra, da linguagem. Isso explica sua incapacidade de rever atos e pedir desculpas e sua falta de reconhecimento próprio como alguém dotado de subjetividade, ou identidade.

Os dois vivem uma história de amor. Um dia ela some. Michel vai estudar Direito e, durante uma audiência de acusação de mulheres por assassinato em Auschwitz, ele a vê enquanto uma das acusadas. Ele poderia salvá-la da sentença, mas não o faz. Se vê profundamente abalado em seus preceitos morais...em sua frágil existência. Não sabe lidar com a memória daquele amor que agora ele relembra moralmente. Michel fica perdido. Hanna é condenada à prisão perpétua... trata-se de um filme sobre ética.

"O Leitor" aproxima o Holocausto do espectador ao construir uma história de amor entre um estudante de Direito e uma assassina de centenas de inocentes. Ele usa esse episódio de horror, que está marcado na memória e na identidade de todos, para ser parte de um romance entre um sujeito dotado de subjetividade e outro, como o filme sugere, debilitado nessa formação simbólica de identidade - pior ainda inserido nos valores de moralidade. $O$ leitor, Michel, representa todos os indiretamente envolvidos com o Holocausto, todos os que se sentem angustiados por ele e que querem compreendê-lo. Todos os que tem memória desse episódio e que se sentem abalados em sua condição de ser humano - a subjetividade.

O amor entre eles significa um processo de identificação entre ambos, como toda relação de amor. E, nesse sentido, o diretor do filme está se perguntando e nos perguntando o que Alain Resnais e Bauman também o fizeram: "Será que eles são diferentes de nós?". Pergunta básica que rege o princípio ético de toda obra que quer representar algo ou alguém. Trata-se de um filme ético sobre ética.

\section{Bibliografia}

BAUMAN, Zygmund ( ) Modernidade e Holocausto

\section{Filmes citados:}

RESNAIS, Alain. Noite e Neblina

O Leitor 